\title{
Caries risk assessment in schoolchildren - a form based on Cariogram ${ }^{\circledR}$ software
}

\author{
Renata Nunes CABRAL ${ }^{1}$, Leandro Augusto HILGERT², Jorge FABER ${ }^{2}$, Soraya Coelho LEAL
}

1- Postgraduate Program of Health Sciences, University of Brasília, Brasília, DF, Brazil.

2- Department of Dentistry, University of Brasília, Brasília, DF, Brazil.

Corresponding address: Renata Nunes Cabral - Faculdade de Ciências da Saúde - UnB - Departamento de Odontologia - Disciplina de Odontopediatria Campus Universitário Darcy Ribeiro, S/N - Asa Norte - 70910-900 - Brasília - DF - Brazil - email: renatancabral@gmail.com

Submitted: February 13, 2014 - Modification: May 14, 2014 - Accepted: June 13, 2014

\section{ABSTRACT}

\begin{abstract}
Tentifying caries risk factors is an important measure which contributes to best 1 understanding of the cariogenic profile of the patient. The Cariogram ${ }^{\circledR}$ software provides this analysis, and protocols simplifying the method were suggested. Objectives: The aim of this study was to determine whether a newly developed Caries Risk Assessment (CRA) form based on the Cariogram ${ }^{\circledR}$ software could classify schoolchildren according to their caries risk and to evaluate relationships between caries risk and the variables in the form. Material and Methods: 150 schoolchildren aged 5 to 7 years old were included in this survey. Caries prevalence was obtained according to International Caries Detection and Assessment System (ICDAS) II. Information for filling in the form based on Cariogram ${ }^{\circledR}$ was collected clinically and from questionnaires sent to parents. Linear regression and a forward stepwise multiple regression model were applied to correlate the variables included in the form with the caries risk. Results: Caries prevalence, in primary dentition, including enamel and dentine carious lesions was $98.6 \%$, and $77.3 \%$ when only dentine lesions were considered. Eighty-six percent of the children were classified as at moderate caries risk. The forward stepwise multiple regression model result was significant $(R 2=0.904 ; p<0.00001)$, showing that the most significant factors influencing caries risk were caries experience, oral hygiene, frequency of food consumption, sugar consumption and fluoride sources. Conclusion: The use of the form based on the Cariogram ${ }^{\circledR}$ software enabled classification of the schoolchildren at low, moderate and high caries risk. Caries experience, oral hygiene, frequency of food consumption, sugar consumption and fluoride sources are the variables that were shown to be highly correlated with caries risk.
\end{abstract}

Keywords: Dental caries. Caries risk. Oral health.

\section{INTRODUCTION}

Dental caries is a multifactorial disease caused by interactions between acidogenic bacteria, biofilm and individual caries risk factors (e.g., saliva composition, fluoride exposure and dietary components $)^{18}$. In a global context, its prevalence is still high, particularly in children ${ }^{21}$. Because dental caries is preventable, Caries Risk Assessment (CRA) is an important tool ${ }^{3}$ assisting the dentist to better understand the cariogenic profile of a patient $t^{4,7}$.

The caries risk profile should be obtained rapidly and easily. The process includes collecting relevant historical data of the patient, such as the medical and dental history. The complex nature of caries risk has led to the development of different protocols that are not all validated. Cariogram ${ }^{\circledR}$, a software program from Sweden, stands out as it has been clinically proven to be effective in evaluating caries risk $^{19}$.

Cariogram ${ }^{\circledR}$ software can be downloaded from the internet. The outcomes are presented graphically to the patient, indicating the probability of avoiding new carious lesions. Cariogram ${ }^{\circledR}$ is based on a set of pathological and protective factors - caries experience, systemic diseases, diet contents and frequency, amount of plaque, mutans streptococci, fluoride sources, saliva secretion and buffer capacity - in addition to the professional clinical judgment. As some factors are considered more relevant than others regarding caries development, different 
weights are given to different factors.

Most information is easily collected at the dental practice, but saliva and bacteria assessment require specific tests which are not frequently performed by a dentist ${ }^{11}$. The use of Cariogram ${ }^{\circledR}$ is limited to places where a computer system is available and where those tests can be performed. For that reason, alternatives ways of performing CRA have been proposed; it is suggested that the best way of implementing CRA in clinical practice would be by the use a form, ensuring that all patients could be assessed systematically in the same manner ${ }^{22}$.

Recently, a form based on the Cariogram ${ }^{\circledR}$ software was proposed ${ }^{17}$. The main differences between the Cariogram ${ }^{\circledR}$ software and the new form include the following: filling in the form does not require a computer; the variables "mutans streptococci", "salivary buffer capacity" and "clinical judgement" are excluded and the form assesses risk based on the sum of values attributed to each etiological factor. Finally, it classifies the patient as having a low, moderate or high caries risk and provides treatment guidelines for each category. This study aimed to determine whether the newly developed CRA form could classify schoolchildren according to their caries risk and to evaluate relationships between caries risk and the variables in the form.

\section{MATERIAL AND METHODS}

\section{Study population}

This study is part of a clinical trial that aims to compare the performance of different sealant materials in the prevention of dental caries. Therefore, children considered at moderate and high caries risk needed to be identified. With that purpose, a survey was carried out in an elementary school located in Paranoá, which is a deprived area of Brazil's Federal District. All 298 children aged 5 to 7 years old and enrolled at school were invited to participate. Children whose parents did not sign the informed consent form and those who needed special care were excluded (Figure 1). The study was approved by the ethics committee of the School of Medicine of the University of Brasília (Reference no. $026 / 2012$ ).

\section{Clinical examination}

Information about the prevalence of dental caries was obtained according to International Caries Detection and Assessment System (ICDAS) $\mathrm{II}^{15}$. Examinations were performed by one trained and calibrated dentist. The dentist was trained in using ICDAS, having completed its e-learning program. Additionally, a pilot study was also conducted at the Brasília University Hospital for the examiner calibration covering other oral conditions that were assessed: toothache, gingival bleeding ${ }^{1}$ and visible plaque $^{3}$.

The oral examinations took place in a dental office located inside the school, with the children sitting on a conventional dental chair under optimal lighting. A plane buccal mirror, WHO-CPI probe and air syringe were used in the clinical examination. First, visible plaque and gingival bleeding were recorded. Then, the examiner cleaned all tooth surfaces with only a toothbrush, after which dental caries was recorded in primary and permanent teeth.

\section{Caries risk assessment}

Caries risk was assessed according to a form based on Cariogram ${ }^{\circledR 17}$, in which seven variables were included, as shown in Figure 2. The form is able to convert into scores the information that was collected about each patient. According to the cariogram built-in algorithm, each variable in the form was weighted at a relevant ratio and the scores were assigned.

The variables "caries experience", "oral hygiene" and "salivary flow" were obtained clinically. For all other variables, the information was retrieved from questionnaires previously sent to parents. For calculating caries experience, data were converted into $\mathrm{dmft} / \mathrm{DMFT}$ scores according to Amorim, et al. ${ }^{5}$ (2012). Regarding the variable "salivary flow", all children were classified as having a normal salivary flow during the clinical examination. After completion of the forms and summing up the scores for all variables, each child was classified as belonging to a low (0-33), moderate $(34-66)$ or high caries risk (>67) group ${ }^{17}$.

\section{Statistical analysis}

First, linear regressions were performed, considering caries risk as a dependent variable and the variables presented in Figure 2 as the

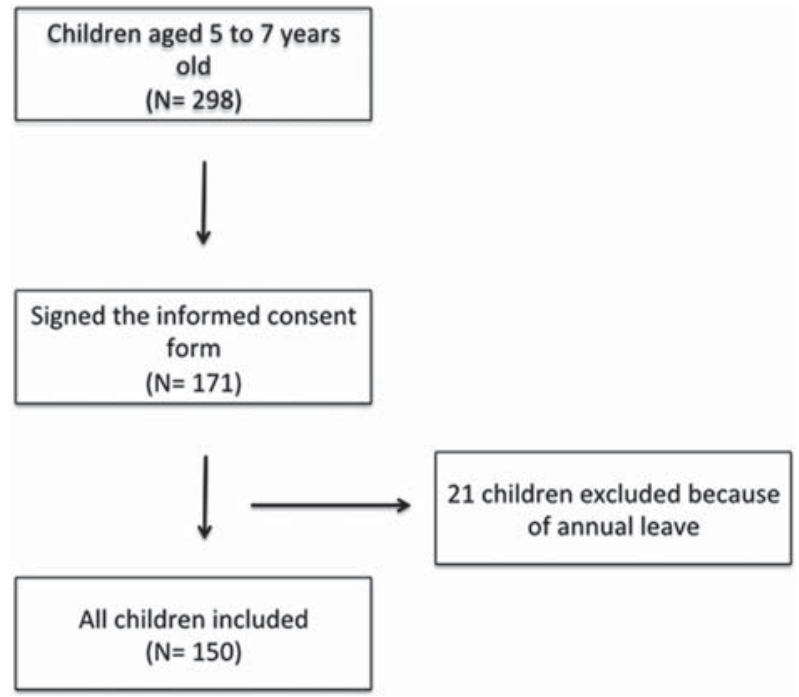

Figure 1- Study flow diagram 


\begin{tabular}{|c|c|c|c|c|c|c|}
\hline \multirow{3}{*}{$\frac{\text { Variable }}{\text { Caries experience }}$} & \multirow{3}{*}{$\begin{array}{c}\text { Description } \\
\text { dmft was considered higher or lower } \\
\text { than average in relation to the age of } \\
\text { the patient }\end{array}$} & \multirow{3}{*}{$\begin{array}{c}\text { Instrument used } \\
\text { dmft }\end{array}$} & \multicolumn{4}{|c|}{ Scores } \\
\hline & & & \multicolumn{2}{|c|}{ Minimum } & \multicolumn{2}{|c|}{ Maximum } \\
\hline & & & 0 & 9 & 11 & 13 \\
\hline Related diseases & $\begin{array}{l}\text { Parents were asked if children } \\
\text { presented diseases related to dental } \\
\text { caries, such as asthma or others }\end{array}$ & Questionnaire & \multicolumn{2}{|c|}{0} & 2 & 4 \\
\hline Sugar consumption & $\begin{array}{c}\text { Parents were asked about the } \\
\text { consumption of fermentable } \\
\text { carbohydrates }\end{array}$ & Questionnaire & 0 & 5 & 13 & 20 \\
\hline $\begin{array}{l}\text { Frequency of food } \\
\text { consumption }\end{array}$ & $\begin{array}{l}\text { Parents were asked about childrens' } \\
\text { diets - the quantity of meals/snacks } \\
\text { consumed per day }\end{array}$ & Questionnaire & 0 & 5 & 13 & 20 \\
\hline Oral hygiene & Visible Plaque Index & $\begin{array}{l}\text { Visible plaque } \\
\text { index }\end{array}$ & 0 & 4 & 8 & 15 \\
\hline Fluoride Sources & $\begin{array}{l}\text { Parents were asked about fluoride } \\
\text { availability }\end{array}$ & Questionnaire & 0 & 5 & 10 & 50 \\
\hline Salivary flow & Suspicion of hyposalivation & $\begin{array}{c}\text { Clinical } \\
\text { Examination }\end{array}$ & 0 & 2 & 5 & 40 \\
\hline
\end{tabular}

$\mathrm{dmft}=$ decayed, missing, filled teeth

Figure 2- Variables assessed, their description, the instrument used and the scores of each variable according to severity

independent ones. The significant variables were

Table 1- Children distribution and mean dmft according to caries risk

\begin{tabular}{ccc}
\hline Caries Risk & Percentage & dmft Mean \pm SD \\
\hline Low & $6 \%$ & $0.10 \pm 0.31$ \\
Moderate & $86 \%$ & $3.58 \pm 3.15$ \\
High & $8 \%$ & $5.75 \pm 4.35$ \\
\hline
\end{tabular}

$\mathrm{dmft}=$ decayed, missing, filled teeth. $\mathrm{SD}=$ standard deviation

included in a forward stepwise multiple regression model. The level of significance for all analysis was set at $5 \%$. The statistical analysis was performed with JMP software version 9.

\section{RESULTS}

\section{Subjects}

The sample population comprised 150 children ( 81 girls and 69 boys) with a mean age and standard deviation of $6.8 \pm 0.62$. The majority of them were from low-income families (less than one Brazilian minimum wage).

\section{Dental caries}

The mean dmft score and standard deviation of the sample was 3.38 \pm 4.5 . Caries prevalence in primary dentition, including enamel and dentine carious lesions, was $98.6 \%$, and $77.3 \%$ when only dentine lesions were considered. Children with a dmft higher than 2 represented $56 \%$ of the sample. The mean dmft score was predominantly influenced by the d-component, as only $18.6 \%$ children presented fillings or extracted teeth. The permanent dentition caries prevalence, including enamel and dentine lesions, was $34 \%$ and when only dentine lesions were considered, $12.6 \%$. The mean DMFT score and standard deviation was $0.22 \pm 1.0$.

\section{Reliability of data collection}

Intra-examiner reliability in diagnosing carious lesions was determined by re-examining $9.3 \%$ of the children. The kappa-coefficient value was 0.924 , showing a high level of reliability.

\section{Caries risk}

The mean dmft scores of the children classified as being at low, moderate or high risk, according to the form based on Cariogram ${ }^{\circledR}$, are presented in Table 1. Distribution of variables scores according to assessed caries risk is presented in Table 2.

In order to establish the variables that influenced caries risk the most, a univariate model was applied, including all variables presented in Figure 2. Results are presented in Table 3 and show that the variable "related diseases" was the only one that did not have a statistically significant effect on the caries risk profile.

The significant factors were then included in a multivariate forward model, showing that the most 
Table 2- Distribution of variables scores occurrence according to caries risk assessed

\begin{tabular}{cccccccccccccc}
\hline & \multicolumn{3}{c}{ Low Risk (n=9) } & \multicolumn{4}{c}{ Moderate Risk (n=129) } & \multicolumn{3}{c}{ High Risk (n=12) } \\
Variable & \multicolumn{3}{c}{ Scores [n(\%)] } & \multicolumn{3}{c}{ Scores [n(\%)] } & \multicolumn{3}{c}{ Scores [n(\%)] } \\
& Min & & & Max & Min & & & Max & Min & & Max \\
\hline Caries & 8 & 1 & 0 & 0 & 22 & 20 & 14 & 73 & 0 & 0 & 1 & 11 \\
experience & $(88.8)$ & $(11.1)$ & $(0)$ & $(0)$ & $(17.0)$ & $(15.5)$ & $(10.9)$ & $(56.6)$ & $(0)$ & $(0)$ & $(8.3)$ & $(91.6)$ \\
Related & 9 & 0 & 0 & 0 & 118 & 2 & 0 & 9 & 10 & 0 & 0 & 2 \\
diseases & $(100)$ & $(0)$ & $(0)$ & $(0)$ & $(91.4)$ & $(1.5)$ & $(0)$ & $(6.9)$ & $(8.3)$ & $(0)$ & $(0)$ & $(16.6)$ \\
Sugar & 0 & 2 & 1 & 6 & 0 & 2 & 24 & 103 & 0 & 0 & 0 & 12 \\
consumption & $(0)$ & $(22.2)$ & $(11.1)$ & $(66.6)$ & $(0)$ & $(1.5)$ & $(18.6)$ & $(79.8)$ & $(0)$ & $(0)$ & $(0)$ & $(100)$ \\
Frequency of & 2 & 6 & 0 & 1 & 13 & 102 & 1 & 13 & 0 & 1 & 0 & 11 \\
consumption & $(22.2)$ & $(66.6)$ & $(0)$ & $(11.1)$ & $(10)$ & $(79)$ & $(0.7)$ & $(10)$ & $(0)$ & $(8.3)$ & $(0)$ & $(91.6)$ \\
Oral hygiene & 2 & 3 & 4 & 0 & 4 & 7 & 37 & 81 & 0 & 0 & 1 & 11 \\
& $(22.2)$ & $(33.3)$ & $(44.4)$ & $(0)$ & $(3.1)$ & $(5.4)$ & $(28.6)$ & $(62.7)$ & $(0)$ & $(0)$ & $(8.3)$ & $(91.6)$ \\
Fluoride & 9 & 0 & 0 & 0 & 84 & 45 & 0 & 0 & 9 & 3 & 0 & 0 \\
sources & $(100)$ & $(0)$ & $(0)$ & $(0)$ & $(65.1)$ & $(34.8)$ & $(0)$ & $(0)$ & $(75)$ & $(25)$ & $(0)$ & $(0)$ \\
Salivary flow & 9 & 0 & 0 & 0 & 129 & 0 & 0 & 0 & 12 & 0 & 0 & 0 \\
& $(100)$ & $(0)$ & $(0)$ & $(0)$ & $(100)$ & $(0)$ & $(0)$ & $(0)$ & $(100)$ & $(0)$ & $(0)$ & $(0)$ \\
\hline
\end{tabular}

relevant variable in caries risk prediction was caries

Therefore, the use of validated instruments for experience (Table 4). guiding the professional in establishing the risk

Table 3- Variables included in the univariated model

\begin{tabular}{lc}
\hline \multicolumn{1}{c}{ Dependent Variable } & Univariate $\mathbf{p ~}$ \\
\hline Caries experience & $<0.0001$ \\
Sugar consumption & 0.0008 \\
Frequency of food consumption & $<0.0001$ \\
Oral hygiene & $<0.0001$ \\
Fluoride sources & $<0.0001$ \\
Related diseases & 0.8287 \\
\hline
\end{tabular}

Table 4- Order of inclusion: the variables in a forward stepwise multiple regression model

\begin{tabular}{ccccc}
\hline Step & Parameter & Estimate & RSquare & Sig Probability \\
\hline 1 & Caries experience & 0.8852817 & 0.308 & $<0.00001$ \\
2 & Oral hygiene & 0.897268 & 0.503 & $<0.00001$ \\
3 & Frequency of food consumption & 0.9335243 & 0.693 & $<0.00001$ \\
4 & Fluoride sources & 0.9275646 & 0.857 & $<0.00001$ \\
5 & Sugar consumption & 0.7430889 & 0.904 & $<0.00001$ \\
\hline
\end{tabular}

\section{DISCUSSION}

Caries Risk Assessment is an important tool that contributes to identification of risk factors and guides the dental professional in the decisionmaking process involved in effective prevention and management of dental caries ${ }^{20}$. The common practice is to assess these factors individually but, as dental caries is a multifactorial disease, more than one factor can predict future caries ${ }^{8}$. profile of a patient is essential. For that reason, the form based on the Cariogram ${ }^{\circledR}$ software, which has been validated in schoolchildren ${ }^{10,13}$, was chosen for use in this investigation. It includes factors involved in the caries process which can be easily assessed, clinically or with questionnaires, without requiring a computer system, thus allowing, in our case, its application in a school located in a lowincome community. The fact that neither salivary buffer capacity nor microbial tests were included 
in the form can be justified by the low predictive values of both tests in relation to dental caries. It is known that in the presence of fluoride, a high number of mutans streptococci and/or lactobacilli may be tolerated in the oral flora without causing any harm to the teeth ${ }^{6}$.

For the univariate model used in the present study, all variables that are included in the form based on Cariogram ${ }^{\circledR}$ were analyzed, except "salivary flow", as none of the children presented clinical aspects of hyposalivation. For the forward stepwise multiple regression model, five variables were included in the analysis and, together, could explain $90.4 \%$ of the caries risk observed in the sample. Individually, the most relevant variable in caries risk prediction was caries experience. These results are corroborated by previous studies using the Cariogram ${ }^{\circledR}$ software, which showed high correlation between caries experience and caries risk profiles ${ }^{9,14}$. Furthermore, caries experience is considered the strongest predictor for future caries, even when other forms of CRA are used ${ }^{11}$.

Results show that the form based on Cariogram ${ }^{\circledR}$ was able to classify the schoolchildren according to the three caries risk categories: low, moderate and high. However, few children were allocated to the low and high categories. Regarding the low risk group, this finding can be ascribed to the high caries prevalence among the children included in the sample. This outcome is in line with a previous study conducted in the same area, where caries prevalence was $67 \%$ for children in the same age group ${ }^{5}$. However, how sure are we that children with a mean dmft of 3.38 ( $86 \%$ of whom were classified as belonging to the moderate risk group) do not belong to the high caries group? These children had a low proportion of missing and filled teeth and a high proportion of decayed teeth.

The variable "caries experience", even though it was the most relevant for caries prediction in the analyzed form, might still not show enough influence on the overall results, since children with an average high dmf score were mostly considered as being at only moderate risk of developing caries, particularly those living in areas with fluoridated water and access to fluoridated toothpaste.

It is important to discuss the weighting given to the "fluoride sources" variable in the form. Among all factors included in the form, the complete absence of a fluoride source is the one that counts the most for the final outcome (50 points). This makes sense as the effectiveness of fluoride in preventing and controlling caries progression has been highly documented ${ }^{16}$. However, in the present study, all children received the lowest score (zero) for the variable "fluoride source", as they live in an area which has fluoridated water (0.07 ppm), and brush their teeth with fluoridated toothpaste.
Another variable that may be responsible for the low differentiation of the children between caries risk groups was "salivary flow", since the absolute majority of the examined children presented normal salivary flow. Firstly, it is common to observe an increase in salivary flow rate with an increase in childhood age ${ }^{12}$. Furthermore, children who suffer from dental caries generally do not present clinical aspects of decreased salivary secretion and, if present, these are often related to systemic diseases $^{9}$. The long-term use of sugary medications, as well as the presence of systemic diseases, is related to an increment in caries risk. Asthma is one condition which probably affects the salivary characteristics $^{2}$. Nevertheless, in the present investigation it was reported by very few parents.

However, the form was effective in classifying the children with the highest dmft scores ( $>4$ ) as having a high risk of developing carious lesions. It was observed that, although these children received the lowest scores for "fluoride sources" and "salivary flow", they got maximum scores for all other factors related to diet and hygiene included on the form, showing the multifactorial etiology of dental caries. These patients would normally score 68 points, just 1 point above the borderline between moderate and high caries risk. Any minimal control of diet or hygiene would already lead them into the moderate risk group. Further discussion of the proper weighting of the variables in the simplified form is encouraged. Also, it is important to note that the outcome of the Cariogram ${ }^{\circledR}$ software is the chance (\%) of avoiding new carious lesions, while the simplified form classifies children according to three risk groups categories. Transformation of Cariogram $^{\circledR}$ results into risk groups has already been performed, using five subgroups according to the chance of avoiding new lesions [very low (0-20\%), low (21-40\%), medium (41-60\%), high $(61-80 \%)$ and very high $(81-100 \%)]^{10}$.

The school in which the survey was carried out is located in an unprivileged community with difficulties in access to health care. This can explain, in part, the high number of children presenting dental treatment needs. Also, this fact reinforces the "feeling" of the authors that the number of children identified as high-risk should be higher. In the Cariogram ${ }^{\circledR}$ software a professional clinical judgement variable allows the examiner to increase the risk for patients that are believed to have a higher chance to develop compared to the data results only. Maybe, in the simplified form, in which this variable is absent, a modification in the caries risk group threshold values could act as the clinical judgment variable of the original software.

The fact that a substantial number of parents did not sign the informed consent form might suggest that their children were caries-free and the 
parents did not feel that exposing them to a dental examination was a necessity. If this assumption is correct, the absence of these children could help to explain the very high prevalence of caries in the studied population and, therefore, some of the results found in the analysis of the form usage. It is suggested that the form based on Cariogram ${ }^{\circledR}$ should be applied in a population with different oral health needs, in order to confirm the ability of the instrument to properly identify subjects who are at low risk.

\section{CONCLUSION}

The form based on the Cariogram ${ }^{\circledR}$ software was able to classify the schoolchildren according to low, moderate and high caries risk, with a large concentration in the moderate risk group, despite the high average dmft. Caries experience, oral hygiene, frequency of food consumption, sugar consumption and fluoride sources are the variables that were shown to be highly correlated with caries risk.

\section{REFERENCES}

1- Ainamo J, Bay I. Problems and proposals for recording gingivitis and plaque. Int Dent J. 1975;25(4):229-35.

2- Alaki SM, Ashiry EA, Bakry NS, Baghlaf KK, Bagher SM. The effects of asthma and asthma medication on dental caries and salivary characteristics in children. Oral Health Prev Dent. 2013;11(2):113-20.

3- Alaluusua S, Malmivirta R. Early plaque accumulation - a sign for caries risk in young children. Community Dent Oral Epidemiol. 1994;22:273-6.

4- Alian AY, McNally ME, Fure S, Birkhed D. Assessment of caries risk in elderly patients using Cariogram Model. J Can Dent Assoc. $2006 ; 72(5): 459-63$.

5- Amorim RG, Figueiredo MJ, Leal SC, Mulder J, Frencken JE. Caries experience in a child population in a deprived area of Brazil, using ICDAS II. Clin Oral Investig. 2012;16(2):513-20.

6- Baehni PC, Guggenheim B. Potential of diagnostic microbiology for treatment prognosis of dental caries and periodontal diseases. Crit Rev Oral Biol Med. 1996;7(3):259-77.
7- Bratthall D, Hansel PG. Cariogram - a multifactorial risk assessment model for a multifactorial disease. Community Dent Oral Epidemiol. 2005;33(4):256-64.

8- Burt BA. Concepts of risk in dental public health. Community Dent Oral Epidemiol. 2005;33(4):240-7.

9- Campus G, Cagetti MG, Sacco G, Benedetti G, Strohmenger L, Lingström P. Caries risk profiles in Sardinian schoolchildren using Cariogram. Acta Odontol Scand. 2009;67(3):146-52.

10- Campus G, Cagetti MG, Sale S, Carta G, Lingström P. Cariogram validity in schoolchildren: a two-year follow-up study. Caries Res. 2012;46(1):16-22.

11- Council on Dental Practice, American Dental Association, Graham FJ. Managing clinical risk: right person, right care, right time. Dent Clin North Am. 2009;53(3):511-22.

12- Crossner CG. Salivary flow rate in children and adolescents. Swed Dent J. 1984;8(6):271-6.

13-Hänsel Petersson G, Twetman S, Bratthall D. Evaluation of a computer program for caries risk assessment in schoolchildren. Caries Res. 2002;36(5):327-40.

14- Holgerson PL, Twetman S, Stecksèn-Blicks C. Validation of an age-modified caries risk assessment program (Cariogram) in preschool children. Acta Odontol Scand. 2009;67(2):106-12.

15- International Caries Detection and Assessment System Coordinating Committee. Criteria manual [online]. 2009 July. [cited May 14 2014]. Available from: https://www.icdas.org/ uploads/ICDAS $\% 20$ Criteria $\% 20$ Document $\% 20$ corrected $\% 20$ 2013.pdf.

16- Murray J]. Efficacy of preventive agents for dental caries. Systemic fluorides: water fluoridation. Caries Res. 1993;27(Suppl 1):2-8.

17- Paris S, Haak R, Meyer-Lueckel H. Diagnostics, treatment decision and documentation. In: Meyer-Lueckel H, Paris S, Ekstrand K. Caries management: science and clinical practice. $1^{\text {st }}$ ed. New York: Thieme; 2013. p. 332.

18- Selwitz RH, Ismail AI, Pitts NB. Dental caries. Lancet. 2007;369:51-9

19- Tellez M, Gomez J, Ellwood R, Ismail AI. Evidence on existing caries risk assessment systems: are they predictive of future caries? Community Dent Oral Epidemiol. 2013;41(1):67-78.

20- Twetman S, Fontana M. Patient caries risk assessment. Monogr Oral Sci. 2009;148:839-43.

21- Vachirarojpisan T, Shinada K, Kawaguchi Y, Laungwechakan P, Somkote T, Detsomboonrat P. Early childhood caries in children aged 6-19 months. Community Dent Oral Epidemiol. 2004;32(2):133-42

22- Young DA, Featherstone JD. Implementing caries risk assessment and clinical interventions. Dent Clin North Am. 2010;54(3):495-505 